\title{
プラント既知情報を利用した適応則
}

\author{
水戸部和 久*・足 立 紀 彦**
}

\section{An Adaptive Law for Partially Known Plants}

\section{Kazuhisa MrtoBE* and Norihiko ADACHI ${ }^{* *}$}

An approach is presented for increasing the speed of parameter convergence in adaptive control systems. In this approach, the adaptive law is modified by using a prior knowledge of plant.

Key Words : adaptive control, parameter convergence, partially known plant

\section{1.はじめに}

適応制御系の制御性能および外乱などに対するロバス ト性を向上するために, 調整パラメータがその目標值へ 速やかに収束することが望ましい1)。パラメー夕収束特 性を向上する方法としては，これまでにパラメー夕調整 ゲインを時変としてパラメー夕誤差を指数減衰させる方 法などが提案されている2). 本研究ではプラントの既知 情報を用いてパラメータ収束特性を改善する方法を提案 する。

適応制御系に含まれる調整パラメータの数はパラメー 夕の収束特性を左右する要因の一つと考えられる。パラ メー夕推定器の内部信号が十分持続的に励起されるとき に(P.E.条件が満足されるときに) 調整パラメー夕の真值 への収束が保証されることが知られているが，パラメー 夕数が多くなれば P.E. 条件を満足するためにプラント への入力信号がより多くの周波数成分を含むことが必要 となる ${ }^{3)}$.

一般に, 適応制御系のパラメー夕推定器に含まれる調 整パラメータ数はプラントに含まれる物理的な未知パラ メータの数より多い.このため, プラント既知情報を用 いてパラメータ推定器の構造を変更することにより推定 パラメータ数を減らす方法が示されている4).

本研究では調整パラメー夕数そのものを減らすのでは なく, 調整パラメータの取り得る值の自由度を減少する 適応則を提案する.この適応則は調整パラメータのそれ ぞれを独立に調整するのではなく, プラント既知情報よ

\footnotetext{
* 山形大学工学部 米沢市城南 4-3-16

** 新潟大学工学部 新潟市五十嵐 2 の町 8050

* Faculty of Engineering, Yamagata Univercity, Yonezawa

** Faculty of Engineering, Niigata Univercity, Niigata (Received February 10, 1992)

(Revised April 23, 1992)
}

り得られる関係式を満足するように拘束を与えながらパ ラメータの調整を行うものである。これによりパラメー 夕推定器の構造および調整パラメー夕数に変更を加えず に，調整パラメータ数を隇少したのと同様の効果を与え ることを目的とする。

\section{2. 誤差方程式}

パラメータ推定のための誤差方程式がつぎのとおり表 わされる場合を問題とする。

$$
\varepsilon(t)=\phi^{T}(t) \xi(t)
$$

ここで, $\varepsilon \in R, \phi \in R^{n \times 1}, \xi \in R^{n \times 1}$ はそれぞれ, パラメー 夕推定誤差, パラメー夕誤差, システム内部信号を表わ し， $\phi$ は推定パラメータ $\theta$ およびその真值 $\theta^{*}$ を用いて

$$
\phi(t)=\theta^{*}-\theta(t)
$$

と表わされるものとする。

\section{3. プラント既知情報}

調整パラメータの真值 $\theta^{*}$ はプラントに含まれる物理 的なパラメータを含む值であり未知である。ここではプ ラント既知情報をパラメータの真值 $\theta^{*}$ に関する既知情 報として扱う。プラントに含まれる物理的パラメータの うち未知なものが $m$ 個とし互いに独立とする. $n>m$ の とき(調整パラメータ数が $m$ より多い場合) $\theta^{*}$ が満足す る既知の関係式が $r$ 個存在すると考え，つぎのように書く.

$$
f\left(\theta^{*}\right)=0
$$

ここで, $f \in R^{r \times 1}$ とし,$r=n-m$ である. $f(\cdot)$ はつぎの 仮定を満足するものとする。

[仮定]

$$
\begin{aligned}
& \text { (1) } f(\theta), \frac{\partial f_{i}(\theta)}{\partial \theta} \quad(i=1 \sim r) \\
& \text { が } \theta \text { の連続関数である. } \\
& \text { (2) } \quad\left(\theta^{*}-\theta\right)^{T} \frac{\partial f_{i}(\theta)}{\partial \theta} f_{i}(\theta) \leqq 0 \quad(i=1 \sim r)
\end{aligned}
$$


12641992 年 10 月

(3) $\frac{\partial f(\theta)}{\partial \theta} \frac{\partial f^{T}(\theta)}{\partial \theta}$ の固有值 $\geqq \alpha>0$

を満足する正数 $\alpha$ が存在する. ここで,

$\frac{\partial f_{i}^{T}}{\partial \theta}=\left(\frac{\partial f_{i}}{\partial \theta_{1}}, \frac{\partial f_{i}}{\partial \theta_{2}}, \cdots, \frac{\partial f_{i}}{\partial \theta_{n}}\right)$

$\frac{\partial f}{\partial \theta}=\left(\begin{array}{c}\frac{\partial f_{1}^{T}}{\partial \theta} \\ \frac{\partial f_{2}^{T}}{\partial \theta} \\ \cdots \\ \frac{\partial f_{r}^{T}}{\partial \theta}\end{array}\right)$

を表わしている.

(3.2) 式は未知変数 $\theta^{*}$ を含むので, 制御系設計に際し てこのまま用いることはできない.しかし， $f\left(\theta^{*}\right)=0$ より，(3.2)式は

$$
\left(\theta^{*}-\theta\right)^{T} \frac{\partial f_{i}(\theta)}{\partial \theta}\left\{f_{i}(\theta)-f_{i}\left(\theta^{*}\right)\right\} \leqq 0
$$

と表わされる。このことは $f_{i}(\theta)$ が $\theta$ 平面上の任意の直 線に沿って単調に増大または減少する関数ならば(3.2) 式は $\theta^{*}$ に無関係に満足されることを意味する。たとえ ば, $f(\theta)$ が定数行列 $K \in R^{r \times n}$ および定数べクトル $\boldsymbol{a}$ $\in R^{r \times 1}$ を用いて，

$$
f(\theta)=K \theta+\boldsymbol{a}
$$

のように表わされる場合には(3.2)式の条件が満足され る.

\section{4. 収束特性の改善}

ここで提案する適応則の目的は内部信号 $\xi$ の P.E. 条件にかかわらず $\theta$ が(3.1)式の関係を満足するように 拘束を与えることである，適応則を次式で与える.

$$
\dot{\theta}=\Gamma\left\{\xi \varepsilon-\sum_{i=1}^{r} \lambda_{i} \frac{\partial f_{i}(\theta)}{\partial \theta} f_{i}(\theta)\right\}
$$

ここで, $\Gamma$ は定数行列であり, $\Gamma=\operatorname{diag}\left(\gamma_{1}, \gamma_{2}, \cdots, \gamma_{n}\right)$, $\gamma_{i}>0$ である. $\lambda_{i}$ は正の設計パラメータである. $\lambda_{i}=0$ と おけ代通常の積分形の適応則となる。つぎのことが成立 する。

\section{《定理 1》}

(2.1)，(4.1)式で表わされるシステムにおいて $f$ が仮 定を満足し, $\xi(・), \dot{\xi}(\cdot)$ が有界ならば $\phi(\bullet)$ は有界であ り,

$$
\begin{aligned}
& \lim _{t \rightarrow \infty} \varepsilon(t)=0 \\
& \lim _{t \rightarrow \infty} f\{\theta(t)\}=0
\end{aligned}
$$

(証明)

$$
V(t)=\frac{1}{2} \phi^{T} \Gamma^{-1} \phi
$$

第 28 巻 第 10 号

$$
\dot{V}=-\varepsilon^{2}+\phi^{T} \sum_{i=1}^{r} \lambda_{i} \frac{\partial f_{i}(\theta)}{\partial \theta} f_{i}(\theta)
$$

仮定 $(2)$ より右辺第 2 項は負なので $\dot{V}(t) \leqq 0$ である. $\xi(\cdot), \dot{\xi}(\cdot)$ が有界であることと仮定 $(1)$ より $\dot{\varepsilon}(\cdot), \dot{\phi}(\cdot)$ は有界であり, $\dot{V}(\cdot)$ は一様連続である.したがって $\lim _{t \rightarrow \infty}$ $\dot{V}(t)=0$. (4.5)式において各項が 0 に収束することよ り, $\varepsilon \rightarrow 0$.

$$
\begin{aligned}
& V_{2}(t)=\frac{1}{2} f\{\theta(t)\}^{T} \Lambda f\{\theta(t)\} \\
& \Lambda=\left(\begin{array}{ccc}
\lambda_{1} & & \\
& \lambda_{2} & \\
& & \\
& & \\
& & \lambda_{r}
\end{array}\right) \text { とおくと } \\
& \dot{V}_{2}=-f^{T} \Lambda \frac{\partial f}{\partial \theta} \Gamma \frac{\partial f^{T}}{\partial \theta} \Lambda f+\delta(\varepsilon)
\end{aligned}
$$

ここで, $\delta(\varepsilon)=f^{T} \Lambda \frac{\partial f}{\partial \theta} \Gamma \varepsilon \xi て ゙ あ り \varepsilon \rightarrow 0$ とすると $\delta \rightarrow 0$ である. $\Gamma$ および $\Lambda$ 要素のなかで最小のものを $\gamma_{\min }$, $\lambda_{\min }$ とおけば，仮定 $(3)$ より

$$
\begin{aligned}
f^{T} \Lambda \frac{\partial f}{\partial \theta} \Gamma \frac{\partial f^{T}}{\partial \theta} \Lambda f & \geqq \gamma_{\min } f^{T} \Lambda \frac{\partial f}{\partial \theta} \frac{\partial f^{T}}{\partial \theta} \Lambda f \\
& \geqq \gamma_{\min } \alpha\left\|f^{T} \Lambda\right\|^{2} \\
& \geqq \gamma_{\min } \alpha \lambda_{\min } \sum_{i=1}^{r} f_{i}^{2} \lambda_{i} \geqq \gamma_{\min } \alpha \lambda_{\min } V_{2}
\end{aligned}
$$

したがって (4.8)式より

$$
\dot{V}_{2} \leqq-\gamma_{\min } \alpha \lambda_{\min } V_{2}+\delta(\varepsilon)
$$

(4.9)式に扑いて $\delta=0$ とおくと $V_{2}$ は指数的に減衰す

る.したがって, $\varepsilon \rightarrow 0$ より $V_{2} \rightarrow 0$ すなおち

$$
\lim _{t \rightarrow \infty} f\{\theta(t)\}=0
$$

以上の考え方は誤差方程式が以下のように動特性を有 する形で与えられる場合にも適用できる。

$$
e(t)=H(s) \phi^{T}(t) \xi(t)
$$

ここで, $e \in R$ は誤差信号, $\phi \in R^{n \times 1}, \xi \in R^{n \times 1}$ は(2.1) 式と同様である. $H(s)$ は強正実な伝達関数とする. 右辺 は伝達関数 $H(s)$ に信号 $\phi^{T}(t) \xi(t)$ が入力された出力を 表わす. 適応則は (4.1) 式と同様に次式で与えられる.

$$
\dot{\theta}=\Gamma\left\{\xi e-\sum_{i=1}^{r} \lambda_{i} \frac{\partial f_{i}(\theta)}{\partial \theta} f_{i}(\theta)\right\}
$$

\section{5. 簡単な例題}

D. C.サーボモータの速度制御を考える.モー夕の速度 応答特性は次式のように一次系でモデル化する。

$$
y(t)=\frac{1}{J s+k_{v}} u(t)
$$

ここで, $u$ は入力電圧, $y$ はモー夕軸の回転角速度を表わ す. $J$ は慣性負荷, $k_{v}$ 注逆起電力などの粘性的な減衰係 数を表わす。このうち $J$ のが未知パラメータとし, $k_{v}$ は既知とする、規範モデルをつぎのとおり与える。 


$$
y_{m}(t)=\frac{1}{J_{m} s+k_{v}} r(t)
$$

ここで, $r$ は規範入力である.このシステムにおいて以下 のように調整パラメータ二つを用いた簡単な適応制御系 を構成できる。

$$
u(t)=k_{r}(t) r(t)+k_{y}(t) y(t)
$$

$k_{r}, k_{y}$ は調整パラメータである. 追従誤差 $e$ を $y_{m}-y$ と 定義すれば，誤差方程式は以下のとおりであり，(4.10) 式の形で表わされる。

$$
\begin{aligned}
e(t)= & \frac{J_{m} / J}{J_{m} s+k_{v}}\left\{\left(k_{v}-\frac{J}{J_{m}} k_{v}-k_{y}(t)\right) y(t)\right. \\
& \left.+\left(\frac{J}{J_{m}}-k_{r}(t)\right) r(t)\right\}
\end{aligned}
$$

ここで, $r(\cdot), \dot{r}(\cdot)$ が有界と仮定する。このとき $e(\cdot)$ が有界であれば $y(\cdot), \dot{y}(\cdot)$ も有界なので, 前節の結果 を直接適用することが可能である.

$k_{r}, k_{y}$ の真值を $k_{r}^{*}, k_{y}^{*}$ で表わすと, 規範モデルと制御系 の動特性が等しくなる条件はつぎのとおり与えられる.

$$
\frac{1}{\frac{1}{k_{r}^{*}} J s+\frac{k_{v}-k_{y}^{*}}{k_{r}^{*}}}=\frac{1}{J_{m} s+k_{v}}
$$

したがって,

$$
k_{r}^{*} k_{v}+k_{y}^{*}-k_{v}=0
$$

を満足する.この関係を(3.1) 式のプラント既知情報と考 えれば，適応則は $(4.11)$ 式より，

$$
\begin{aligned}
& \dot{k}_{r}(t)=\gamma_{1}\left[r(t) e(t)-\lambda k_{v}\left\{k_{v} k_{r}(t)+k_{y}(t)-k_{v}\right\}\right] \\
& \dot{k}_{y}(t)=\gamma_{2}\left[y(t) e(t)-\lambda\left\{k_{v} k_{r}(t)+k_{y}(t)-k_{v}\right\}\right]
\end{aligned}
$$

このシステムの正弦入力に対する応答を計算機シミュ レーションにより Fig. 1 に示す. 各パラメータの值は以 下のものを用いた。

$$
\begin{aligned}
& J=2.0, J_{m}=1.0, k_{v}=1.0, \gamma_{1}=10, \\
& \gamma_{2}=10, \lambda=10,
\end{aligned}
$$

入力信号は $r=1.0+2 \sin (5 t)$ と与えている.

Fig. 2 は $\lambda=0$ とし, 適応則を通常の積分形適応則とした 場合のシミュレーションである.

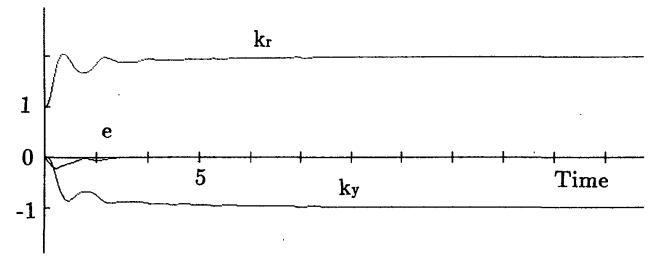

Fig. 1 Time response of the system with the modified adaptive law

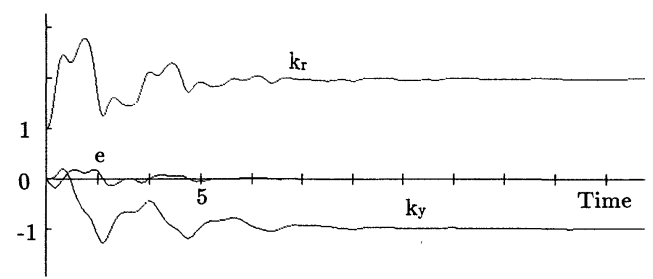

Fig. 2 Time response of the system with the conventional adaptive law

\section{6. おわりに}

適応則に拘束項を付加することにより収束特性を改善 する一手法を示した。

シミュレーション結果によれば，適応ゲインが収束す るまでの過渡的な変動の大きさも小さく抑えられること から，パラメー夕同定中の適応制御系で入力が過度に大 きくなることを防ぐ効果も期待できる.

本手法で用いるプラント既知情報が誤差を含む場合に はシステムの安定性に悪影響を与えることが考えられ，

この点に関して今後検討が必要である.

\section{参 考 文 献}

1）新中新二：適応アルゴリズム，産業図書（1990）

2）岩井，足立，井上：指数減衰性を有する適応調整則とその 適応観測器への応用, 計測自動制御学会論文集, 20-5, 460/ 462 (1984)

3) S. Boyd and S. Sastry : Nesessary and Sufficient Condition for Parameter Convergence in Adaptive Control, Automatica, 22-6, 629/639 (1986)

4) S. Sastry and M. Bodson: Adaptive Control, PrenticeHall, 257/266 (1989) 